\title{
Case series of unusual presentations of
}

\section{Thyrotoxicosis}

\author{
Dr Meenakshi Parsad, Dr Samuel King, Dr Livoon Chong,Dr Kimberley Lambert \\ Royal Hampshire County Hospital, Winchester
}

\section{- Introduction}

-Thyrotoxicosis is a relatively common condition affecting $1-2 \%$ of women and $0.1-0.2 \%$ of men ${ }^{1}$. Common symptoms are usually straightforward and easily identified especially in the younger population. It is known that such is not always the case in the elderly who can present with arrhythmia or unexplained weight loss $^{1}$. However, rare presenting features such as confusion and headache in the younger population have been sparsely published in the literature as case reports ${ }^{2,3}$.

-We hereby report two young cases of Graves' Thyrotoxicosis presenting within a 4 months' period to our Acute Medical Unit with rare presenting features of thyrotoxicosis.

-Due to the uncommon presenting complaints, the initial diagnostic pathway was misled.

\section{- Case Series}

- The first case is a 45-year-old female with a 4-day history of headache which started acutely. She described a daily morning headache which improved through the day. Other symptoms were dizziness, weakness, nausea, palpitations and intermittent dyspnoea. She was noted to be in sinus tachycardia. Other examination findings were unremarkable. Thyroid Function Tests requested in view of the tachycardia.

- The second case is a 48-year-old male who presented with acute confusion. He was found naked and doubly incontinent by his family. He was noted to have intermittent word-finding difficulties and therefore initially referred by ED department to the Stroke Consultant who requested routine TFTs. A sinus tachycardia was noted then.

\section{Investigations and Management}

Case1: CT brain was the next step and this was completely unremarkable. The TFTs results were noted to be TSH $<0.01 \mathrm{mu} / \mathrm{L}, \mathrm{FT} 4>155 \mathrm{pmol} / \mathrm{L}$ and FT3 $30.8 \mathrm{pmol} / \mathrm{L}$.. The plan was still to proceed with lumbar puncture to rule out a sub-arachnoid haemorrhage if clinically symptomatic despite starting treatment for thyrotoxicosis. On reviewing the patient however, her symptoms were much improved on carbimazole and propranolol and the lumbar puncture was cancelled.

Case 2:the working diagnosis was encephalitis once stroke was ruled out and the patient had CT brain which was unremarkable. He then had a lumbar puncture which revealed CSF with 41 white cells (mainly Lymphocytes) and 32 red cells, with negative culture and PCR. After 2 days, the TFTs results were available and these showed completely suppressed TSH with FT4 48 pmol/L. TSH Receptor antibody was requested and the patient was started on carbimazole 20mg OD.

CT Brain Case 1

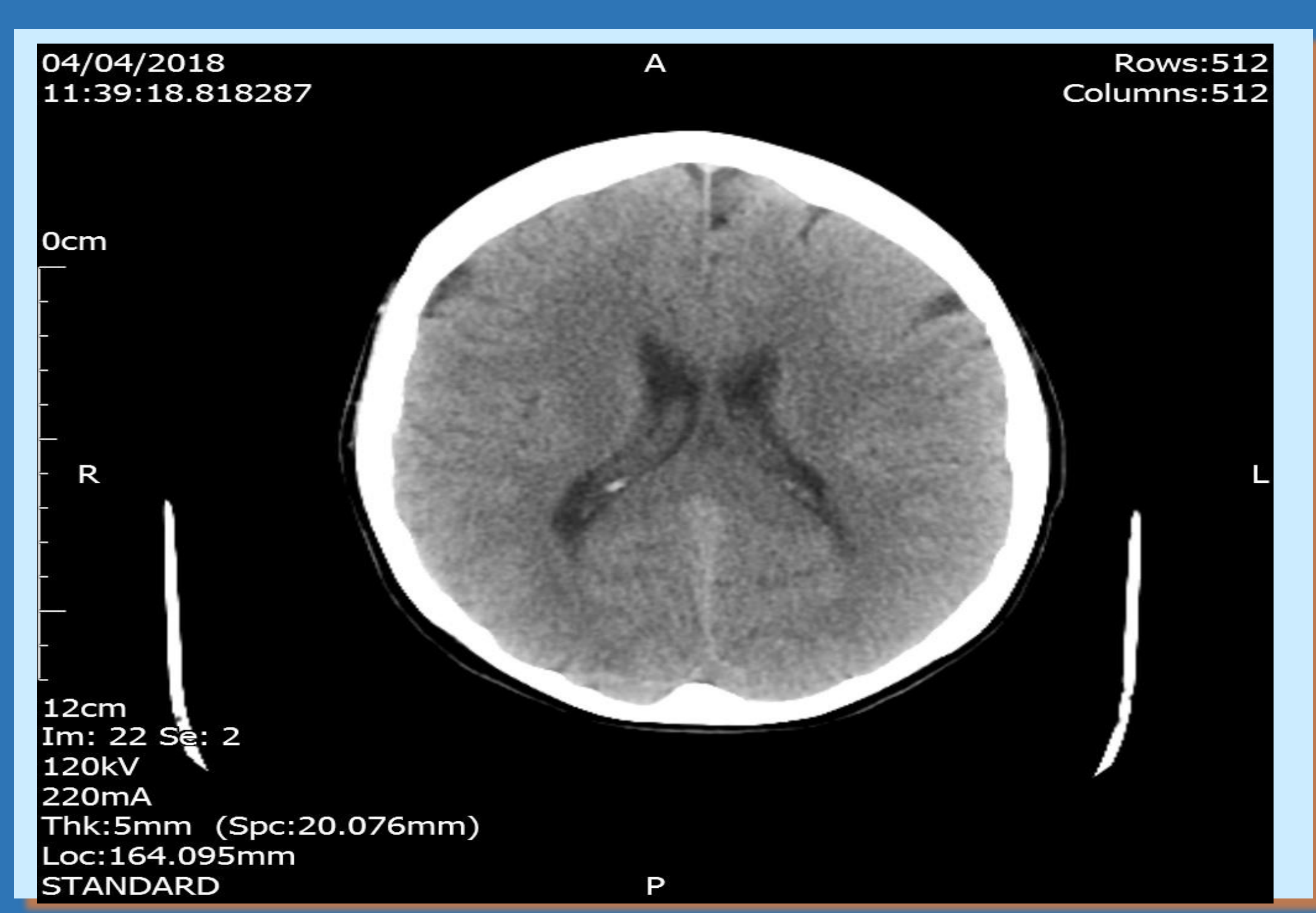

Outcome

\section{Case 1:}

-Thyroid Peroxidase antibodies were negative, but TSH Receptor antibodies were positive.

-The patient was safely discharged on Carbimazole 40mg OD.

-At 6 weeks clinic review, she complained of no headache and had $\mathrm{TSH}<0.01 \mathrm{mu} / \mathrm{L}$ and FT4 $16.4 \mathrm{pmol} / \mathrm{L}$

Case 2

-Thyroid peroxidase antibodies and TSH Receptor antibodies were both positive

-The patient was started on carbimazole 20mg OD

-At 3-month review, he improved clinically and had TSH 2.09 and FT4 8.6.
CT Brain Case 2

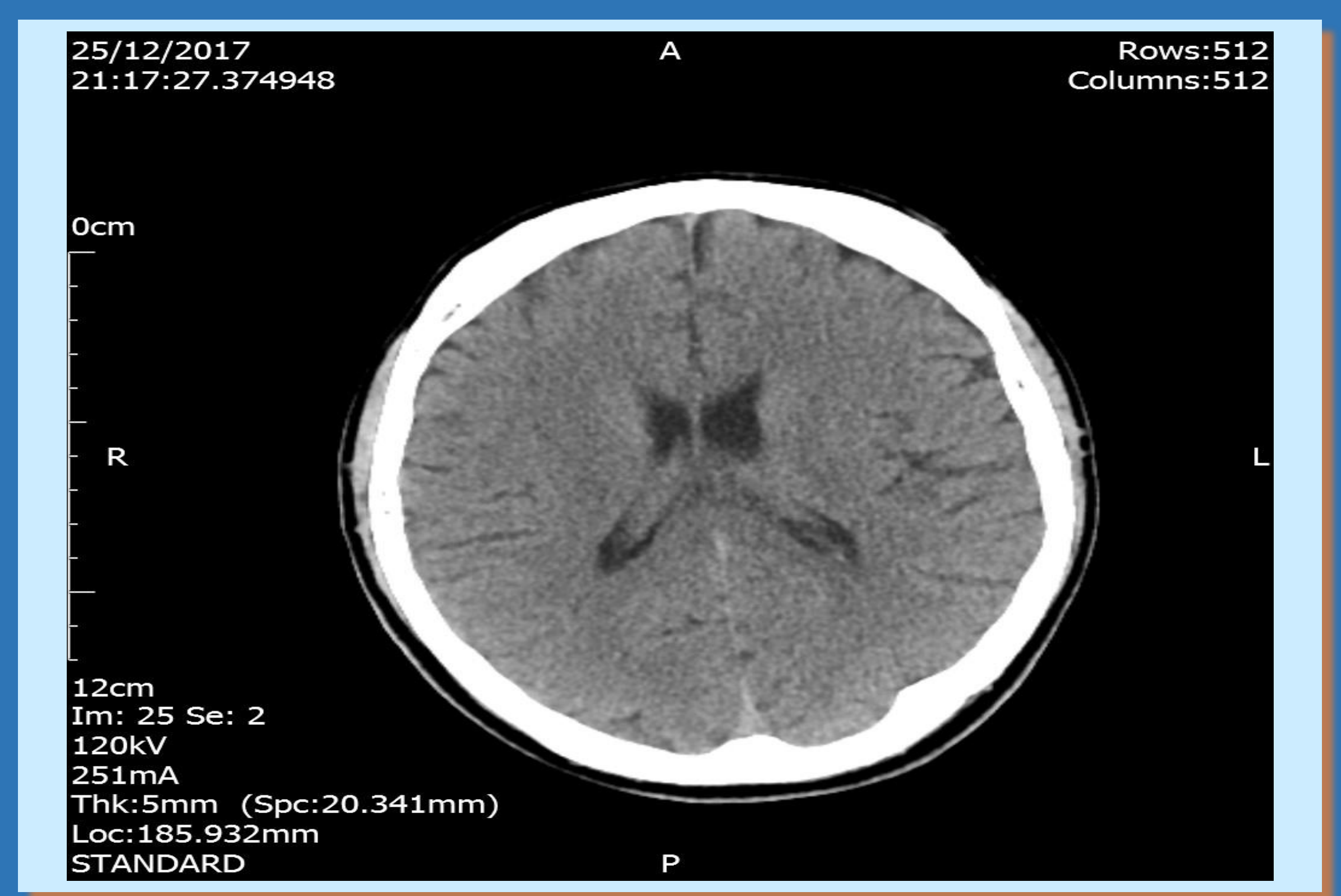

\section{Discussion and Conclusion}

- Thyrotoxicosis can present in unusual ways as demonstrated.

- The classic presenting complaints might not be present, but pointers may include unexplained tachycardia as in both of our cases

- More sinister causes such as sub-arachnoid haemorrhage or encephalitis are sensible differential diagnoses as they would more commonly present with an acute onset headache as in case 1 or acute confusion with odd behaviour as in case 2 .

- This small case series calls for more unusual presentations of thyrotoxicosis to be reported to increase our knowledge and awareness at large.

\section{References}

Melmed et al Williams Textbook of Endocrinology 2016, Elsevier

Stone J. et al Thyrotoxicosis presenting with headache Cephalgia 2007 June 27 (6): 561-2.

Adeleye et al Unusual presentation of thyrotoxicosis- a case report and review of literature West Afr J. Med 2005 Jul-Sep; 24(3):274-7 